\title{
A comparative study of periarticular bone lesions in rheumatoid arthritis and psoriatic arthritis
}

\author{
Stephanie Finzel, ${ }^{1}$ Matthias Englbrecht, ${ }^{1}$ Klaus Engelke, ${ }^{2}$ Christian Stach, ${ }^{1}$ \\ Georg Schett ${ }^{1}$
}

Additional data (supplementary figure) are published online only. To view these files please visit the journal online (http://ard.bmj. com).

${ }^{1}$ Department of Internal Medicine 3 and Institute for Clinical Immunology, University of Erlangen-Nuremberg, Erlangen, Germany Institute of Medical Physics, University of ErlangenNuremberg, Erlangen, Erlangen, Germany

\section{Correspondence to} Professor Georg Schett, Department of Internal Medicine 3, Rheumatology and Immunology, University of Erlangen-Nuremberg, Krankenhausstrasse 12, Erlangen D-91054, Germany; georg.schett@uk-erlangen.de

Accepted 9 August 2010 Published Online First 11 October 2010

\begin{abstract}
Background Psoriatic arthritis (PsA) and rheumatoid arthritis (RA) are both destructive arthritides but may differ substantially in their periarticular bone changes. Objectives To investigate the differences in the structural changes of periarticular bone in patients with PsA and RA by a high-resolution imaging technique designed to visualise the bone architecture.
\end{abstract}

Methods 30 patients with PsA and 58 patients with RA received a $\mu \mathrm{CT}$ scan to compare structural bone changes in the metacarpophalangeal joints of the dominantly affected hand. Number, extent, form and distribution of bone erosions, osteophytes and cortical thinning were recorded. In addition, the size and depth of bone erosions and the size of osteophytes were determined.

Results Patients with PsA and RA had the same number of bone erosions, but they were less severe and overall smaller in size and depth in PsA. Erosions in PsA were mostly $\Omega$-shaped and tubule-shaped, whereas U-shaped lesions were most typical for RA. Erosions in PsA were more evenly distributed, lacking the strong preponderance for the radial sites found in RA. Osteophytes were increased in number, extent and size in PsA as compared with RA, often affecting the entire circumference of bone ('bony corona').

Conclusions High-resolution $\mu \mathrm{CT}$ imaging shows profound differences in periarticular bone changes between PsA and RA. Smaller $\Omega$-shaped and tubuleshaped bone erosions as well as large sometimes corona-shaped osteophytes are typical for PsA. These data suggest that mechanisms of bone repair may be more active in PsA than in RA.

\section{INTRODUCTION}

Rheumatoid arthritis (RA) and psoriatic arthritis (PsA) share a chronic progressive disease course with little or no chance for spontaneous regression. Structural damage is a feature of both RA and PsA and reflects the spread of joint inflammation to cartilage and bone, resulting in progressive damage and irreversible impairment of the joint function. Earlier studies based on radiography have suggested that the burden of structural damage in RA and PsA is comparable. ${ }^{1}$

RA and PsA share similar pathophysiological concepts and some, but not all, of the molecular players are identical. Importantly, RA and PsA differ in the anatomical localisation of inflammatory lesions. This is reflected by a different pattern of joint involvement in both diseases and also by differences in the microanatomical localisation of inflammation within a single joint. ${ }^{2}{ }^{3}$ Current concepts of RA suggest it is a primarily synovial disease. In consequence, structural damage in RA is strongly linked to synovitis and is especially prominent at those sites, where (1) the synovial membrane inserts into the juxta-articular periosteum and where (2) the insertion sites of collateral ligaments are located. In contrast, PsA is considered to be substantially different as it affects the insertion sites of the tendons. These entheses consist of fibrocartilage, which is a specialised tissue that transduces mechanical signals from tendons to bone. ${ }^{4}$

Imaging studies by ultrasound and MRI have shown that RA and PsA affect different compartments in large joints. ${ }^{5}$ This observation is probably true for the small joints as well, but owing to the close co-localisation of the entheses and the synovium, such distinction is difficult. ${ }^{67}$ Importantly, enthesitis can spread to the synovium and cause secondary synovitis, which shares some features of synovitis in RA, although there are also molecular differences such as lower levels of the M1-derived monokines, tumour necrosis factor and interleukin $1 .{ }^{8}$

In this study we tested whether the differences in joint inflammation between RA and PsA are also reflected by differences in structural damage. Conventional radiography clearly supports the concept that PsA is an erosive bone disease similar to RA. ${ }^{2}{ }^{9}$ Bone erosion leading to a break in the cortical lining is a typical sign for PsA. On the other hand, PsA has a bone anabolic component leading to bony spur formation. ${ }^{9}{ }^{10}$ To study this in more detail we performed a comparative study on the structural changes of periarticular bone to better define the morphological differences between RA and PsA in vivo.

\section{MATERIALS AND METHODS \\ Patients' characteristics}

Thirty patients with PsA (15 women and 15 men) from the rheumatology outpatient clinic of the University Clinic of Erlangen were included into the study. Mean $( \pm$ SD) age was $52.4 \pm 13.4$ years, mean $( \pm S D)$ disease duration $8.6 \pm 6.9$ years. All patients had polyarticular PsA with involvement of the hand and finger joints. None of the patients showed rheumatoid factor or anti-citrullinated protein antibodies. Average 28-joint count Disease Activity Score (DAS28) was $3.49 \pm 1.31$, mean C-reactive protein (CRP) level was $7.92 \pm 10.22 \mathrm{mg} / \mathrm{l}$. All patients with PsA were treated with disease-modifying antirheumatic drugs, $75 \%$ of them receiving methotrexate, $7 \%$ leflunomide and $35 \%$ tumour necrosis factor 
blockers. All patients with PsA fulfilled the CASPAR classification criteria for PsA. ${ }^{11}$ The characteristics of the 58 patients with RA have been described previously. ${ }^{12}$ Briefly, 42 of them were female and 16 male with a mean $( \pm$ SD) age of $53.8 \pm$ 13.2 years and a mean $( \pm S D)$ disease duration of $6.5 \pm 7.8$ years. Seventy per cent of patients showed rheumatoid factor and $75 \%$ anti-citrullinated protein antibodies. Average DAS28 was $4.08 \pm 1.42$, mean CRP level was $15.44 \pm 28.98 \mathrm{mg} / \mathrm{l}$. All patients with RA were treated with disease-modifying antirheumatic drugs and fulfilled the American College of Rheumatology classification criteria for RA. ${ }^{13}$

Standard measures of disease activity such as the DAS28 score, erythrocyte sedimentation rate (ESR) and CRP level as well as rheumatoid factor and anti-cyclic citrullinated peptide antibody positivity were assessed. In addition, current treatment with disease-modifying antirheumatic drugs as well as biological agents was recorded. The study was performed in accordance with the Declaration of Helsinki. Approval from the local ethics committee and national radiation safety agency (Bundesamt für Strahlenschutz) as well as informed consent was obtained for the study.

\section{Imaging procedures}

$\mu \mathrm{CT}$ of the metacarpophalangeal (MCP) joint region of the clinically most affected hand was performed with an XtremeCT (SCANCO Medical AG, Brüttisellen, Switzerland) at a solution of $82 \times 82 \times 82 \mu \mathrm{m}$ voxel size. Therefore the hand was positioned in stretched posture and padded. Scanning was performed within a region of 80 slices distal and 242 slices proximal of the surface of the metacarpal head III. Scan time was 8 min.

\section{Evaluation of images}

MCP joints of the second, third and fourth digit were evaluated for the presence and size of bone erosions as well as osteophytes in 530 two-dimensional slices. Erosions were defined as a juxta-articular break within the cortical shell. Osteophytes were defined as bony protrusions from the juxta-articular cortical shell. In addition, analysis for changes in cortical bone surface was done by performing three-dimensional (3D) reconstruction images. Bone surface structure was examined after volume rendering by the open source DICOM viewer Osirix V3.2 and by $3 \mathrm{D}$ reconstruction software provided by Scanco Medical AG. Both programs use a threshold-based algorithm. Constant thresholds were used for all subjects. To assess the exact localisation of erosions, osteophytes and surface changes, the frequency distribution of these lesions was assessed in four different compartments: the palmar (I), ulnar (II), dorsal (III) and radial quadrant (IV), at both the metacarpal heads and bases of first phalangeal bone.

Bone erosions, osteophytes and surface changes in each joint region (metacarpal heads and phalangeal bases of the MCP2-4 joints) were scored semiquantitatively by four grades (0-3), as described previously. ${ }^{12}$ Briefly, grading was based on the maximum diameter of the cortical break for bone erosions (grade 0 : no erosion, grade 1: erosion of $<2 \mathrm{~mm}$, grade 2 : erosion of $>2 \mathrm{~mm}$, grade 3 : large destruction of the joint), the maximum distance between the 'original' and new cortical lining (=maximal height) for osteophytes (grade 0: no osteophyte, grade 1: osteophyte of $<1 \mathrm{~mm}$, grade 2 : osteophyte of $>1 \mathrm{~mm}$, grade 3: large and diffuse osteophytes) and the percentage of area affected by cortical surface changes (grade 0: no surface changes, grade 1: surface changes affecting $<25 \%$ of surface area, grade $2: 25-50 \%$ of surface area affected, grade $3:>50 \%$ of surface area affected). Furthermore, the number of erosions and osteophytes in the MCP joints, the size and depth of bone individual erosions and the size of osteophytes were measured. All scans were scored in anonymous form by a rheumatologist.

\section{Statistics}

Number, extent, size and depth of cortical breaks, number, extent and size of osteophytes and the extent of surface changes were compared in patients with RA and PsA. Gaussian distribution was tested by Kolmogorov-Smirnov test for each item. As findings were considered to be not Gaussian distributed, the Mann-Whitney U test was used for the comparison of groups. Therefore, Spearman $r$ bivariate correlation coefficients were computed for cumulative erosion, osteophyte and cortical surface change scores, erosion and osteophyte frequency scores, age, disease duration, DAS28, ESR and CRP to test for coherence. Calculations were done using SPSS program version 17.0 .

\section{RESULTS \\ Comparative analysis of the prevalence, numbers, extent and shape of bone erosions in PsA and RA}

We first compared bone erosions in RA and PsA. The prevalence of cortical breaks was high in both RA and PsA. Overall, 93.1\% of patients with PsA showed at least one cortical break at the MCP joints 2, 3 or 4, which was even slightly higher than in RA $(87.5 \%)$. In both PsA and RA erosive lesions were more commonly found at the MCP2 $(82.1 \%$ and $75 \%$, respectively) and MCP3 (85.7\% and $73.3 \%$, respectively) than the MCP4 joint (57.0\% and $33.9 \%$, respectively). The mean number of erosive lesions detected in the MCP2-4 joints did not differ between patients with PsA (6.3 \pm 1.3$)$ and patients with RA (6.1 \pm 0.9$)$ (figure $1 \mathrm{~A})$. Also, there was no difference in the number of

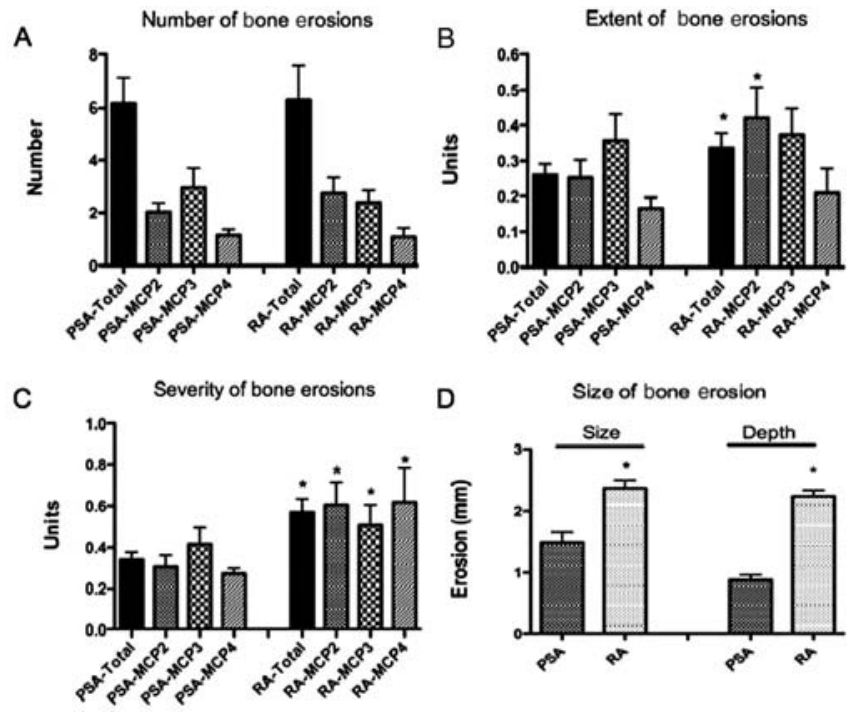

Figure 1 Comparative analysis of the number, extent and size of bone erosions in psoriatic arthritis (PsA) and rheumatoid arthritis (RA). (A) Mean (SEM) numbers of bone erosions in the metacarpophalangeal (MCP) joint compartment of patients with PsA and RA. (B) Mean extent of erosive lesions according to a semiquantitative score (0-3) in patients with PsA and RA. (C) Selective analysis of the extent of existing erosive lesions by semiquantitative score $(0-3)$ in patients with PsA and RA. (D) Quantitative analysis of the width of the cortical break and the depth of the erosive lesion in patients with PsA and RA. ${ }^{*} \mathrm{p}<0.01$. 
lesions when the MCP2 (PsA: $2.0 \pm 0.4$, RA: $2.9 \pm 0.7$ ), MCP3 (PsA: $2.9 \pm 0.7, \mathrm{RA}: 2.4 \pm 0.4$ ) and MCP4 (PsA: $1.1 \pm 0.9$, RA: $1.1 \pm 1.0)$ joints were selectively analysed.

With respect to extent of lesions, cortical breaks with a diameter of $>2 \mathrm{~mm}$ (Stach et al ${ }^{12}$ ) were found in only $39.7 \%$ of PsA but $60.2 \%$ of patients with RA. Semiquantitative scoring of bone erosions (grade $1-3$ ) showed significantly more severe lesions in RA $(0.33 \pm 0.04)$ than in PsA $(0.25 \pm 0.03$; $\mathrm{p}<001)$ (figure 1B). This difference was based on a more severe affection of the MCP2 joint in RA $(0.42 \pm 0.08)$ than in PsA $(0.25 \pm 0.04)$, whereas the extent of lesions in the MCP3 (RA: $0.37 \pm 0.07 ;$ PsA: $0.36 \pm 0.07)$ and in the MCP4 joints (RA: $0.20 \pm$ 0.07 ; PsA: $0.16 \pm 0.03)$ was comparable. Very similar results were obtained when non-erosive joints were excluded and only those with bone erosions were assessed (RA: $0.56 \pm 0.17$, PsA: $0.34 \pm 0.09$ ) (figure 1C). Direct quantitative assessment of erosive lesions showed that the mean size of cortical breaks in PsA was $1.33 \mathrm{~mm}$, but $2.3 \mathrm{~mm}$ in RA ( $\mathrm{p}<0.01)$ (figure 1D). Mean depth of bone erosions was $0.86 \mathrm{~mm}$ in PsA and $2.2 \mathrm{~mm}$ in RA ( $p<0.01)$ (figure 1D).

Based on their form we could define three distinct types of erosive lesions: 'U'-shaped lesions with a wide cortical break and smaller lesion ground, ' $\Omega$ '-shaped lesions with a small cortical break (bottleneck) and a large erosion underneath and ' $T$ ' (tubule)-shaped lesions representing cortical tunnels (figure 2). 'U'-shaped erosions were typical for RA (85.7\%) and much less common in PsA (39.0\%), which typically showed ' $\Omega$ '-shaped lesions (68.0\%). Also, ' $T$ '-shaped lesions, which were rare in RA, were found in significant numbers in PsA (35.7\% in PsA vs $5.4 \%$ in $\mathrm{RA}$ ). The fine distribution of erosions was substantially different between RA and PsA (figure 3A,B). Erosions in RA had a typical predilection for the radial sites of the second and third metacarpal heads. In PsA, erosions were also found at the palmar sites of the MCP2 and MCP3 joints in an almost identical number and extent and involvement of the base of the phalanges was more consistently found.

\section{Comparative analysis of osteophytes in RA and PsA}

Our previous investigations in patients with RA and healthy individuals showed that even very small bony spurs of $<0.5 \mathrm{~mm}$ are detectable by $\mu \mathrm{CT}$ imaging. We therefore aimed to compare osteophytes in RA and PsA. Osteophytes were found in only $16 \%$ of patients with RA and in $100 \%$ of patients with PsA. In PsA, osteophytes were more common at MCP2 (82\%) and MCP3 joints (86\%) than at the MCP4 joints (50\%). The overall mean number of osteophytes detected in the MCP2-4 joints was $11.6 \pm 1.3$ in PsA and much lower in patients with RA $(2.1 \pm 0.2)(p<001$; figure $4 A)$. This difference was found in the MCP2 (PsA: $5.1 \pm 0.6, \mathrm{RA}: 1.1 \pm 0.2$ ), MCP3 (PsA: $4.7 \pm 0.7, \mathrm{RA}$ : $0.8 \pm 0.1)$ and MCP4 (PsA: $1.8 \pm 0.3$, RA: $0.3 \pm 0.07)$ joints.

With respect to their extent, osteophytes with a diameter of $>1 \mathrm{~mm}$ in diameter were found in only $5 \%$ of patients with RA but $97 \%$ of patients with PsA. Semiquantitative scoring of osteophytes (grades $1-3$ ) showed significantly more severe lesions in PsA $(0.26 \pm 0.04)$ than in RA $(0.11 \pm 0.01 ; \mathrm{p}<001)$ (figure $4 \mathrm{~B})$. This difference was based on an overall increased extent of osteophytes in the MCP2 (PsA: $0.24 \pm 0.04$; RA: $0.20 \pm 0.03$ ), MCP3 (PsA: $0.37 \pm 0.08$; RA: $0.10 \pm 0.02$ ) and MCP4 (PsA: $0.16 \pm 0.03$; RA: $0.04 \pm 0.01)$ joints in PsA. Very similar results were obtained when regions with unaltered joints were excluded and only those with osteophytes were assessed (PsA: $0.26 \pm 0.04$; RA: $0.13 \pm 0.02$; figure 4C). Direct quantitative assessment of osteophytes showed a mean size of $1.23 \mathrm{~mm}$ in PsA and $0.45 \mathrm{~mm}$ $(p<0.01)$ in RA (figure 4D).
A
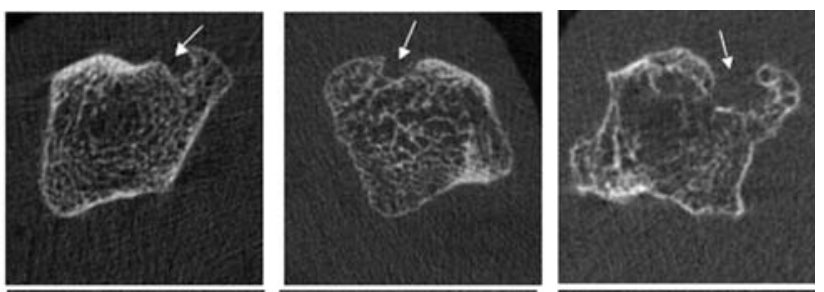

B
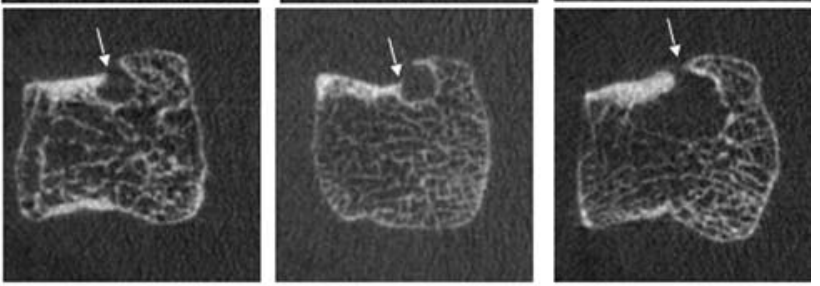

C
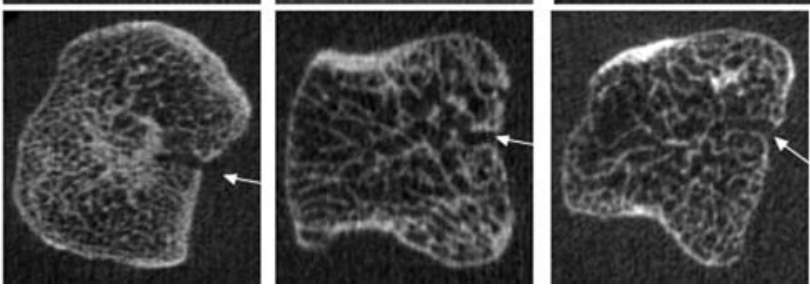

Figure 2 Patterns of bone erosions according to their forms in patients with psoriatic arthritis (PsA). (A) Examples of U-shaped bone erosions which are found in patients with PsA and rheumatoid arthritis (RA). (B) Examples of $\Omega$-shaped bone erosions which are typical for patients with PsA showing a bottleneck-shaped cortical break. (C) Examples of $T$ (tubule)-shaped bone erosions which form channels reaching the bone marrow and are typically found at the palmar joint compartment of patients with PsA.

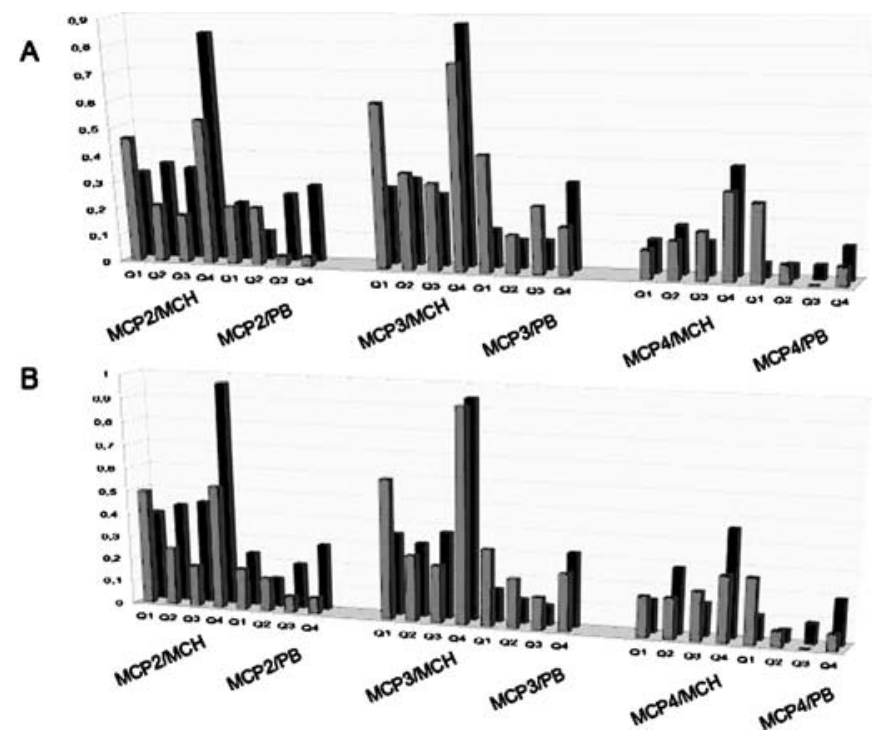

Figure 3 Comparative analysis of the distribution of erosive lesions in psoriatic arthritis (PsA) and rheumatoid arthritis (RA). (A) Mean number and $(B)$ extent of erosive lesions in the metacarpal heads ( $\mathrm{MCH}$ ) and the phalangeal heads (PB) of the second, third and fourth metacarpophalangeal (MCP) joints are shown. The four different quadrants (01: palmar, 02: ulnar, 03: dorsal, 04: radial) of each joint were analysed separately. Light grey bars indicate PsA, black bars indicate RA.

Whereas osteophytes in RA, if present, are limited to the dorsal and palmar sites, which is in accordance with the distribution in healthy aged individuals, lesions in PsA are far more widespread (figure 4E), often covering all four sites of the joint appearing as a bony corona (figure $5 \mathrm{~A}$ ). 

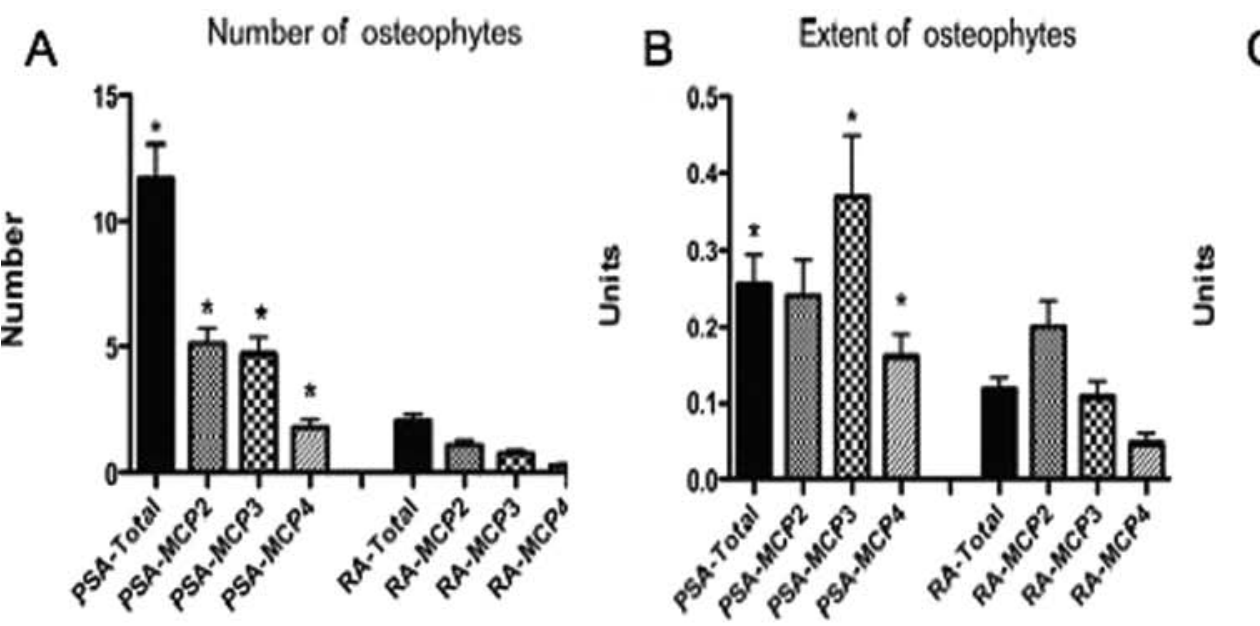
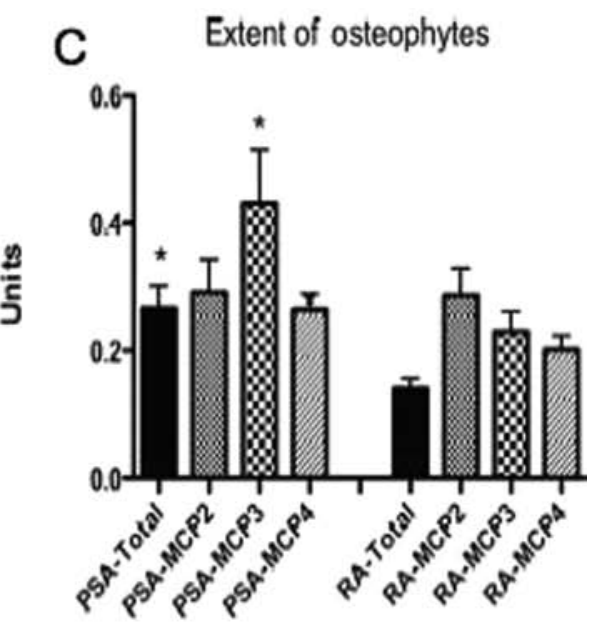

D

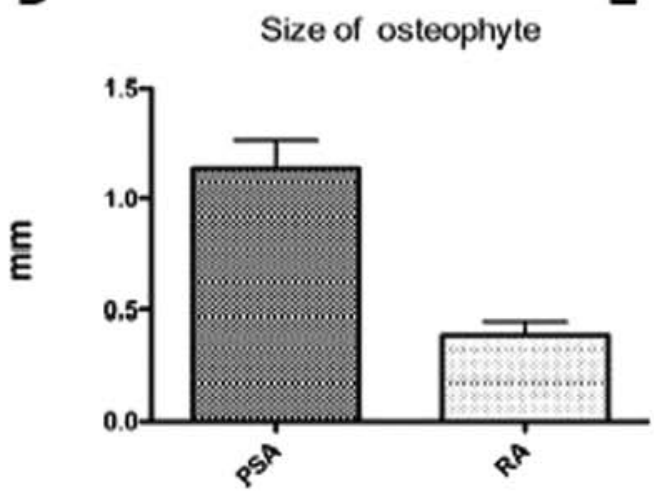

E

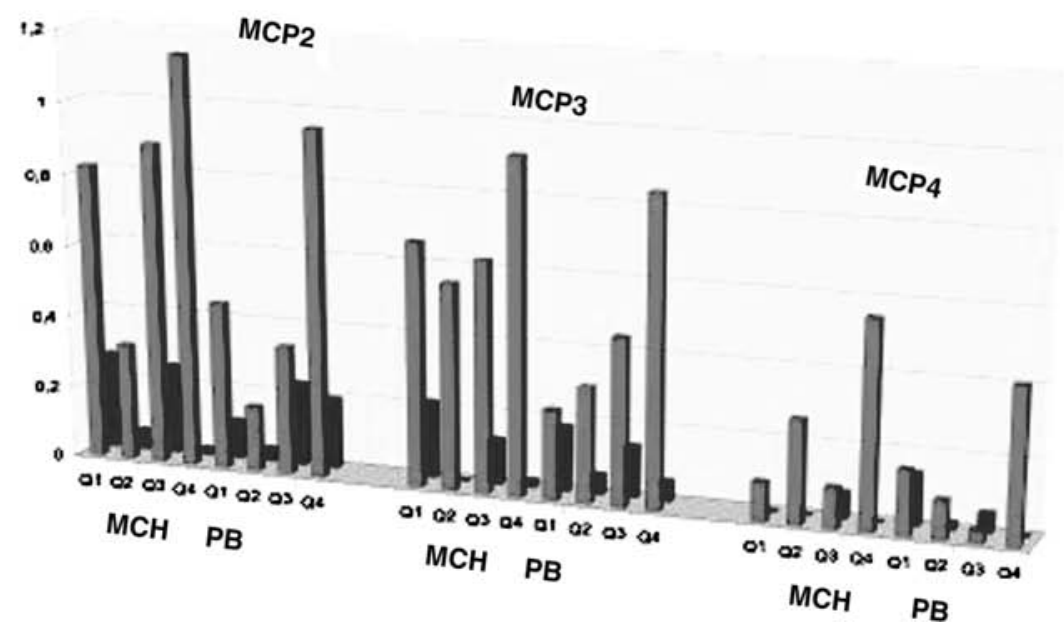

Figure 4 Comparative analysis of osteophytes in psoriatic arthritis (PsA) and rheumatoid arthritis (RA). (A) Mean (SEM) numbers of osteophytes in the metacarpophalangeal (MCP) joint compartment of patients with PsA and RA. (B) Mean extent of osteophytes according to a semiquantitative score (0-3) in patients with PsA and RA. (C) Selective analysis of the extent of existing osteophytes by semiquantitative score (0-3) in patients with PsA and RA. (D) Quantitative analysis of the size of osteophytes in patients with PsA and RA. (E) Mean number of osteophytes in the metacarpal heads (MCH) and the phalangeal heads (PB) of the second, third and fourth MCP joints are shown. The four different quadrants (Q1: palmar, 02: ulnar, 03: dorsal, 04: radial) of each joint were separately analysed. Light grey bars indicate PsA, black bars indicate RA. ${ }^{*} p<0.01$.

\section{Comparative analysis of cortical thinning/fenestration in RA and PsA}

We next examined cortical thinning and fenestration, which is an alteration of the cortical surface but not a cortical break. ${ }^{12}$ These surface changes were found in $79 \%$ of patients with RA and $93 \%$ of patients with PsA. More extended lesions covering more than $25 \%$ of the cortical bone surface were found in $37 \%$ of patients with RA and $43 \%$ of patients with PsA. The mean extent of surface changes in PsA was similar to that in $\mathrm{RA}-0.33 \pm 0.03$ and $0.38 \pm 0.04$, respectively (figure $5 \mathrm{~B}, \mathrm{C}$ ). There was no difference between PsA and RA in the extent of MCP2 (PsA: $0.65 \pm 0.08$; RA: $0.60 \pm 0.07$ ) and MCP3 (PsA: $0.54 \pm 0.08$; RA: $0.59 \pm 0.07)$ lesions, whereas lesions were less severe in the MCP4 joint in PsA $(0.23 \pm 0.14)$ than in RA $(0.43 \pm 0.06, p=0.038)$. Surface changes had no predilection for the radial joint compartment but were evenly distributed in patients with PsA (online supplementary figure 1).

\section{Correlations of bone lesions in PsA with clinical parameters of the disease}

When correlating the individual bone changes in PsA with demographic and disease-specific variables, we found that the cumulative scores of the number and extent of erosions were strongly related to the disease duration of PsA (table 1). There was no apparent relation of erosion scores with the actual disease activity as measured by CRP, ESR or DAS28 at the time of the CT scan. Erosion scores were also related to cumulative osteophyte and surface changes scores, suggesting that the different features of structural bone changes in PsA are at least in part related to each other. In contrast to bone erosions, osteophyte scores were linked to age, but not to disease duration. This was profoundly different from bone erosions and surface changes, which were also related to disease duration in PsA.

\section{DISCUSSION}

In this study we compared the structural changes of joints affected by PsA and RA by using a technique that specifically allows detection of the fine structural changes of bone. By investigating the prevalence, extent and exact localisation of periarticular bone changes in patients with PsA and RA, we found clear differences but also some important similarities between these two major inflammatory joint diseases. Based on (1) the apparent differences among RA and PsA in conventional radiography 91014 ; (2) the distinct characteristics of 

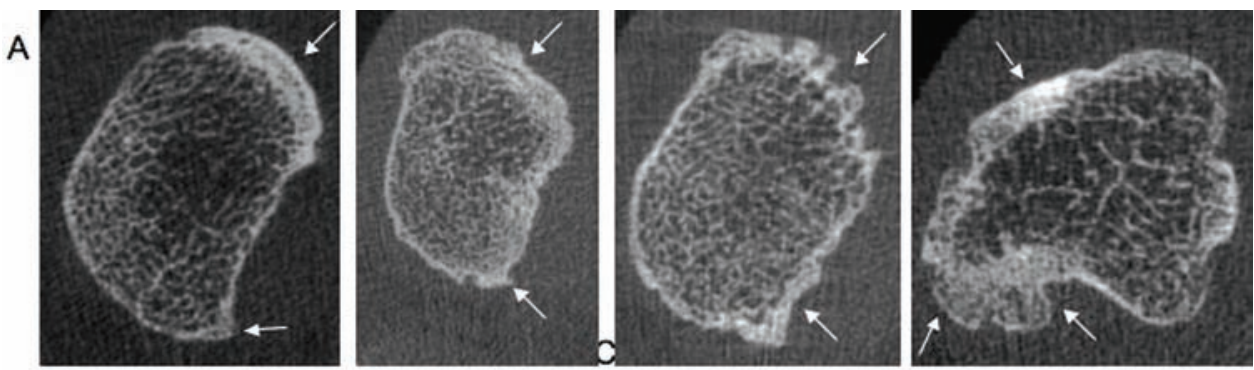

B

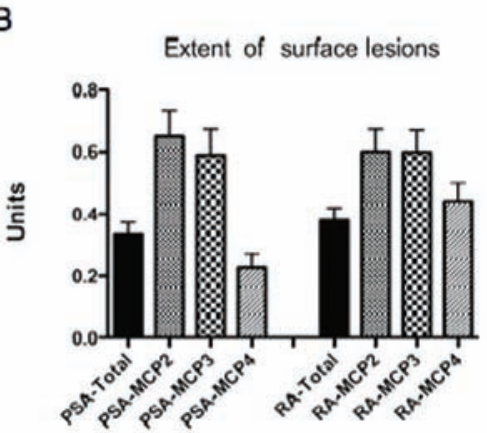

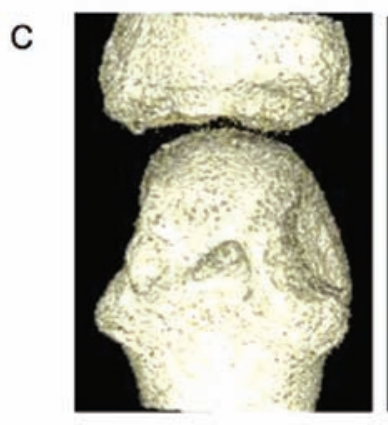

PSA

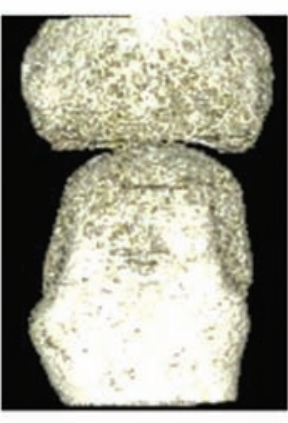

RA

Figure 5 Osteophytes and comparative analysis of cortical surface lesions in psoriatic arthritis (PsA) and rheumatoid arthritis (RA). (A) Examples of osteophytes in patients with PsA typically showing a corona-shaped pattern with widespread involvement of the cortical bone. (B) Mean extent of surface changes according to a semiquantitative score (0-3) in patients with PsA and RA. (C) Examples of surface changes in patients with PsA and RA. MCP, metacarpophalangeal.

Table 1 Correlation of structural changes with clinical parameters.

\begin{tabular}{|c|c|c|c|c|c|c|c|c|c|c|c|c|}
\hline & & Age & $\begin{array}{l}\text { Body mass } \\
\text { index }\end{array}$ & $\begin{array}{l}\text { Disease } \\
\text { duration }\end{array}$ & $\begin{array}{l}\text { C reactive } \\
\text { protein }\end{array}$ & $\begin{array}{l}\text { Disease } \\
\text { activity } \\
\text { score } 28\end{array}$ & $\begin{array}{l}\text { Erythrocyte } \\
\text { sedimentation } \\
\text { rate }\end{array}$ & $\begin{array}{l}\text { Erosion } \\
\text { count }\end{array}$ & $\begin{array}{l}\text { Erosion } \\
\text { score }\end{array}$ & $\begin{array}{l}\text { Osteophyte } \\
\text { count }\end{array}$ & $\begin{array}{l}\text { Osteophyte } \\
\text { score }\end{array}$ & Surface score \\
\hline \multirow[t]{2}{*}{ Age } & $r$ & 1.000 & & & & & & & & & & \\
\hline & $\mathrm{p}$ & & & & & & & & & & & \\
\hline \multirow[t]{2}{*}{ Body mass index } & $r$ & -0.036 & 1.000 & & & & & & & & & \\
\hline & $p$ & 0.856 & & & & & & & & & & \\
\hline \multirow[t]{2}{*}{ Disease duration } & $r$ & -0.253 & -0.346 & 1.000 & & & & & & & & \\
\hline & $\mathrm{p}$ & 0.195 & 0.072 & & & & & & & & & \\
\hline \multirow[t]{2}{*}{ C-reactive protein } & $r$ & 0.041 & $0.397^{*}$ & -0.353 & 1.000 & & & & & & & \\
\hline & $\mathrm{p}$ & 0.836 & 0.037 & 0.066 & & & & & & & & \\
\hline \multirow{2}{*}{$\begin{array}{l}\text { Disease activity } \\
\text { score } 28\end{array}$} & $r$ & 0.051 & 0.165 & -0.129 & $0.461 *$ & 1.000 & & & & & & \\
\hline & $\mathrm{p}$ & 0.796 & 0.400 & 0.514 & 0.013 & & & & & & & \\
\hline \multirow{2}{*}{$\begin{array}{l}\text { Erythrocyte } \\
\text { sedimentation rate }\end{array}$} & $r$ & 0.288 & 0.286 & -0.122 & 0.288 & 0.188 & 1.000 & & & & & \\
\hline & $p$ & 0.137 & 0.139 & 0.538 & 0.137 & 0.338 & & & & & & \\
\hline \multirow[t]{2}{*}{ Erosion count } & $r$ & 0.170 & 0.140 & $-0.433^{*}$ & 0.246 & 0.160 & 0.345 & 1.000 & & & & \\
\hline & $\mathrm{p}$ & 0.386 & 0.476 & 0.021 & 0.206 & 0.415 & 0.072 & & & & & \\
\hline \multirow[t]{2}{*}{ Erosion score } & $r$ & 0.200 & 0.044 & $-0.418^{*}$ & 0.222 & 0.134 & 0.306 & $0.970 * *$ & 1.000 & & & \\
\hline & $p$ & 0.308 & 0.824 & 0.027 & 0.255 & 0.496 & 0.114 & 0.000 & & & & \\
\hline \multirow[t]{2}{*}{ Osteophyte count } & $r$ & $0.395^{*}$ & 0.170 & -0.236 & -0.032 & 0.171 & 0.162 & 0.344 & $0.381 *$ & 1.000 & & \\
\hline & $\mathrm{p}$ & 0.037 & 0.388 & 0.226 & 0.871 & 0.384 & 0.411 & 0.073 & 0.045 & & & \\
\hline \multirow[t]{2}{*}{ Osteophyte score } & $r$ & 0.173 & 0.030 & -0.011 & -0.042 & 0.271 & 0.263 & 0.317 & 0.361 & $0.808 * *$ & 1.000 & \\
\hline & $p$ & 0.380 & 0.880 & 0.957 & 0.831 & 0.163 & 0.177 & 0.100 & 0.059 & 0.000 & & \\
\hline \multirow[t]{2}{*}{ Surface score } & $r$ & 0.130 & -0.132 & -0.344 & -0.242 & -0.086 & -0.136 & 0.339 & $0.393^{*}$ & $0.424 *$ & 0.337 & 1.000 \\
\hline & $\mathrm{p}$ & 0.509 & 0.503 & 0.073 & 0.215 & 0.663 & 0.489 & 0.077 & 0.038 & 0.024 & 0.080 & \\
\hline
\end{tabular}

${ }^{*} \mathrm{p} \leq 0.05 ;{ }^{* *} \mathrm{p} \leq 0.01$.

r, Spearman correlation coefficients.

inflammation in PsA in MRI and ultrasound ${ }^{15-24}$ and (3) our recent experience in visualising and quantifying periarticular skeletal changes by $\mu \mathrm{CT}$ imaging, ${ }^{12}$ we aimed to compare the periarticular bone changes in RA and PsA.

Similar to RA, PsA is associated with substantial bone erosions. $^{2} 25$ Indeed, with respect to the number of erosions in MCP joints, PsA is indistinguishable from RA. However, erosive lesions in PsA are smaller than those found in RA. The reason for this finding is not fully clear but may be based on an increased repair potential in PsA, which may limit the size of erosions in PsA. This concept is in fact supported by several observations: (1) the impact of joint inflammation seems to be comparable in RA and PsA given that the number of erosions and the extent of surface changes are similar in the two diseases. (2) There is a major difference in osteophyte formation, which reflects a bony repair response, between RA and PsA. Whereas 
osteophytes in RA are rare and usually small, they are highly prevalent, widespread and more severe in PsA. Finally, (3), erosive lesions in PsA have a profoundly different shape than their counterparts in RA: whereas RA shows U-shaped erosions PsA typically has $\Omega$-shaped lesions, which are composed of a bottleneck and larger erosion underneath. Such lesions are predominantly located in the bone marrow and may result from bone marrow inflammation, which is a key finding in MRI scans of patients with PsA. Moreover, the formation of the bottleneck may require repair responses attempting to close the cortical break by bony apposition. Tubule-shaped lesions appear as widened cortical bone channels. In fact, the high resolution of the $\mu \mathrm{CT}$ allows the visualisation of physiological cortical bone channels, which are used by blood vessels to penetrate cortical bone. Tubule-shaped lesions are typically found at these sites but are much wider. This finding suggests that inflammatory tissue may use cortical bone channels for trafficking from the synovium to the bone marrow and vice versa, leading to a widening of these channels by osteoclast-mediated bone erosions.

In summary, these data show that bone lesions in PsA are substantially different from those in RA. These data support previous notions of a different pathophysiological concept of RA and PsA. PsA shows smaller bone erosions than RA and their form and distribution is also substantially different from RA. Moreover, osteophytes, which are uncommon and small in $\mathrm{RA}$, are a hallmark of PsA and often affect the entire circumference of periarticular bone, including even the dorsal and palmar regions of the joint. This finding may indicate a different repair potential in PsA and RA, which might be based on less profound suppression of bone formation in patients with PsA than in patients with RA. As some of the molecular factors of structural remodelling, including the control of bone formation, are currently discovered, ${ }^{26}{ }^{27}$ these clinical aspects of the differences of structural damage in PsA and RA may guide our therapeutic strategies to specifically interfere with structural joint remodelling in PsA and RA.

Funding This study was supported by the Deutsche Forschungsgemeinschaft (FG 661/TP4 and SPP1468-IMMUNOBONE), the Bundesministerium für Bildung und Forschung (BMBF); ANCYLOSS and IMMUNOPAIN, the MASTERSWITCH, KINACEPT and ADIPOA projects of the European Union, the Interdisciplinary Centre for Clinical Research and the ELAN fund of the University of Erlangen-Nuremberg.

\section{Competing interests None.}

Patient consent Obtained.

Ethics approval This study was conducted with the approval of the ethics committee of the medical faculty of the Friedrich-Alexander University of ErlangenNuremberg, Krankenhausstraße 12, 91054 Erlangen, Germany.

Provenance and peer review Not commissioned; externally peer reviewed.

\section{REFERENCES}

1. Rahman $\mathbf{P}$, Nguyen $E$, Cheung $C$, et al. Comparison of radiological severity in psoriatic arthritis and rheumatoid arthritis. J Rheumatol 2001;28:1041-4.

2. Gladman DD, Shuckett R, Russell ML, et al. Psoriatic arthritis (PSA)-an analysis of 220 patients. $0 \mathrm{~J}$ Med 1987;62:127-41.
3. McGonagle D. Imaging the joint and enthesis: insights into pathogenesis of psoriatic arthritis. Ann Rheum Dis 2005;64(Suppl 2):ii58-60.

4. Benjamin M, McGonagle D. The enthesis organ concept and its relevance to the spondyloarthropathies. Adv Exp Med Biol 2009;649:57-70.

5. McGonagle D. Imaging the joint and enthesis: insights into pathogenesis of psoriatic arthritis. Ann Rheum Dis 2005;64(Suppl 2):ii58-60.

6. Jevtic V, Watt I, Rozman B, et al. Distinctive radiological features of small hand joints in rheumatoid arthritis and seronegative spondyloarthritis demonstrated by contrastenhanced (Gd-DTPA) magnetic resonance imaging. Skeletal Radiol 1995;24:351-5.

7. Marzo-Ortega H, Tanner SF, Rhodes LA, et al. Magnetic resonance imaging in the assessment of metacarpophalangeal joint disease in early psoriatic and rheumatoid arthritis. Scand J Rheumatol 2009;38:79-83.

8. Vandooren B, Noordenbos T, Ambarus C, et al. Absence of a classically activated macrophage cytokine signature in peripheral spondylarthritis, including psoriatic arthritis. Arthritis Rheum 2009;60:966-75.

9. Gladman DD, Stafford-Brady F, Chang $\mathrm{CH}$, et al. Longitudinal study of clinical and radiological progression in psoriatic arthritis. J Rheumatol 1990;17:809-12.

10. Wassenberg S, Fischer-Kahle V, Herborn G, et al. A method to score radiographic change in psoriatic arthritis. Z Rheumatol 2001;60:156-66.

11. Taylor W, Gladman D, Helliwell P, et al.CASPAR Study Group. Classification criteria for psoriatic arthritis: development of new criteria from a large international study. Arthritis Rheum 2006;54:2665-73

12. Stach CM, Bäuerle M, Englbrecht $\mathrm{M}$, et al. Periarticular bone structure in rheumatoid arthritis patients and healthy individuals assessed by high-resolution computed tomography. Arthritis Rheum 2010;62:330-9.

13. Arnett FC, Edworthy SM, Bloch DA, et al. The American Rheumatism Association 1987 revised criteria for the classification of rheumatoid arthritis. Arthritis Rheum 1988;31:315-24.

14. van der Heijde D, Sharp J, Wassenberg S, et al. Psoriatic arthritis imaging: a review of scoring methods. Ann Rheum Dis 2005;64:ii61-4.

15. Porter GG. Psoriatic arthritis. Plain radiology and other imaging techniques. Baillieres Clin Rheumatol 1994;8:465-82.

16. Wakefield RJ, Conaghan PG, Jarrett S, et al. Noninvasive techniques for assessing skeletal changes in inflammatory arthritis: imaging technique. Curr Opin Rheumatol 2004;16:435-42.

17. Ory PA, Gladman DD, Mease PJ. Psoriatic arthritis and imaging. Ann Rheum Dis 2005;64(Suppl 2):ii55-7.

18. McQueen F, Lassere M, Østergaard M. Magnetic resonance imaging in psoriatic arthritis: a review of the literature. Arthritis Res Ther 2006;8:207.

19. Wiell C, Szkudlarek M, Hasselquist M, et al. Ultrasonography, magnetic resonance imaging, radiography, and clinical assessment of inflammatory and destructive changes in fingers and toes of patients with psoriatic arthritis. Arthritis Res Ther 2007:9:R119.

20. D'Agostino MA, Said-Nahal R, Hacquard-Bouder C, et al. Assessment of peripheral enthesitis in the spondylarthropathies by ultrasonography combined with power Doppler: a cross-sectional study. Arthritis Rheum 2003:48:523-33.

21. Stone MA, White LM, Gladman DD, et al. Significance of clinical evaluation of the metacarpophalangeal joint in relation to synovial/bone pathology in rheumatoid and psoriatic arthritis detected by magnetic resonance imaging. J Rheumatol 2009;36:2751-7.

22. McQueen FM, Dalbeth N, Doyle A. MRI in psoriatic arthritis: insights into pathogenesis and treatment response. Curr Rheumatol Rep 2008;10:303-10.

23. Tan AL, Grainger AJ, Tanner SF, et al. A high-resolution magnetic resonance imaging study of distal interphalangeal joint arthropathy in psoriatic arthritis and osteoarthritis: are they the same? Arthritis Rheum 2006;54:1328-33.

24. Ostergaard M, McQueen F, Wiell C, et al. The OMERACT psoriatic arthritis magnetic resonance imaging scoring system (PsAMRIS): definitions of key pathologies, suggested MRI sequences, and preliminary scoring system for PsA Hands. J Rheumatol 2009;36:1816-24.

25. Bond SJ, Farewell VT, Schentag CT, et al. Predictors for radiological damage in psoriatic arthritis: results from a single centre. Ann Rheum Dis 2007;66:370-6

26. Schett G, Sieper J. Inflammation and repair mechanisms. Clin Exp Rheumatol 2009;27(4 Suppl 55):S33-5.

27. Lories RJ, Baeten DL. Differences in pathophysiology between rheumatoid arthritis and ankylosing spondylitis. Clin Exp Rheumatol 2009;27(4 Suppl 55):S10-14. 

lesions in rheumatoid arthritis and psoriatic arthritis

Stephanie Finzel, Matthias Englbrecht, Klaus Engelke, Christian Stach and Georg Schett

Ann Rheum Dis 2011 70: $122-127$ originally published online October 11, 2010

doi: 10.1136/ard.2010.132423

Updated information and services can be found at:

http://ard.bmj.com/content/70/1/122

\section{These include:}

Supplementary Supplementary material can be found at:

Material http://ard.bmj.com/content/suppl/2010/11/15/ard.2010.132423.DC1.ht $\mathrm{ml}$

References This article cites 27 articles, 9 of which you can access for free at: http://ard.bmj.com/content/70/1/122\#BIBL

Email alerting Receive free email alerts when new articles cite this article. Sign up in the service box at the top right corner of the online article.

Topic Articles on similar topics can be found in the following collections

Collections

Degenerative joint disease (4250)

Musculoskeletal syndromes (4541)

Connective tissue disease (3901)

Immunology (including allergy) (4679)

Rheumatoid arthritis (2981)

\section{Notes}

To request permissions go to:

http://group.bmj.com/group/rights-licensing/permissions

To order reprints go to:

http://journals.bmj.com/cgi/reprintform

To subscribe to BMJ go to:

http://group.bmj.com/subscribe/ 